\title{
Effectiveness of disinfectant treatments for inactivating Piscirickettsia salmonis
}

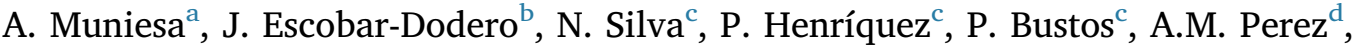 \\ F.O. Mardones ${ }^{\mathrm{b}, *}$ \\ ${ }^{a}$ Facultad de Veterinaria, Universidad de Zaragoza, Instituto Agroalimentario de Aragón (IA2) (Universidad de Zaragoza-CITA), c/Miguel Servet 177, 50013 Zaragoza, \\ Spain \\ ${ }^{\mathrm{b}}$ Escuela de Medicina Veterinaria, Facultad de Ecología y Recursos Naturales, Universidad Andrés Bello, Av. República 440, Santiago 8370251, Chile \\ ${ }^{\mathrm{c}}$ ADL Diagnostic Chile Ltda., Laboratorio de Diagnóstico y Biotecnología, Puerto Montt, Chile \\ ${ }^{\mathrm{d}}$ Department of Veterinary Population Medicine, College of Veterinary Medicine University of Minnesota Saint Paul, MN, USA
}

\section{A R T I C L E I N F O}

\section{Keywords:}

Disinfectants

Chlorine

Glutaraldehyde

Hypochlorite

Peracetic acid

Peroxide

Piscirickettsia salmonis

Biosecurity

Salmon farming

\begin{abstract}
A B S T R A C T
This short communication investigated in vitro differences between commercial disinfectants types $(n=36)$, doses of application, and time of action in the elimination of Piscirickettsia salmonis, the most important bacterium affecting farmed salmon in Chile. Seven different treatments were examined, including active and inactive chlorine dioxides, glutaraldehyde, hypochlorite disinfectants and detergents, peracetic acid, peroxides and other miscellaneous methods A 3 replicate set of each of the sample groups was stored at $20{ }^{\circ} \mathrm{C}$ and $95 \%$ relative humidity and retested after 1, 5 and $30 \mathrm{~min}$ with varying doses (low, recommended and high doses). Multiple comparison tests were performed for the mean log CFU/ml among different disinfectant types, dose (ppm) and time of exposure (minutes) on the reduction of $P$. salmonis. Overall, disinfection using peracetic acid, peroxides, and both active and inactive chlorine dioxides caused significantly higher reduction of $>7.5$ log $\mathrm{CFU} / \mathrm{ml}$ in samples, compared to other tested sanitizers. The lowest reduction was obtained after disinfection with hypochlorite detergents. As expected, as doses and time of action increase, there was a significant reduction of the overall counts of $P$. salmonis. However, at lowest doses, only use of paracetic acids resulted in zero counts. Implementation of effective protocols, making use of adequate disinfectants, may enhance biosecurity, and ultimately, mitigate the impact of $P$. salmonis in farmed salmon.
\end{abstract}

\section{Introduction}

The bacterium Piscirickettsia salmonis is the causal agent for salmonid rickettsial septicemia (SRS) or Piscirickettsiosis, reported first in Chile in 1989 (Bravo and Campos, 1989). SRS is responsible for $50-97 \%$ of the total disease-specific salmon mortality in the Chilean salmon industry; accounting for annual direct and indirect losses of about US\$ 700 million (M. Medina, pers. comm.). SRS has evolved over time; each new outbreak is increasingly insidious and refractory to treatments, and each has shown increased bacterial virulence, clinical and pathological severity and variable presentation under similar conditions of species, age and management measures (Leal and Woywood, 2007; Marshall et al., 2007; Rozas and Enriquez, 2014). In Norway and Canada (Olsen et al., 1997; Cusack et al., 2002), SRS is prevalent as well; however, in those countries, consequences of infection with this pathogen are believed to be less detrimental than in Chile. Reasons why SRS affects Chile more severely than other major salmon producers are yet-to-be elucidated. $P$. salmonis can survive for extended periods in sea water but is rapidly inactivated in fresh water (Lannan and Fryer, 1994). SRS is a salt water disease, and current control strategies include vaccination and use of antibiotics therapies, which have shown to be unsuccessful to protect throughout the growing at salt-water farms or fattening stage. However, fish may be exposed to $P$. salmonis throughout the entire salmon production cycle, from fresh-water hatcheries to marine sites and final harvesting. Compared to other bacterial infections, SRS disease dynamics are not fully understood as $P$. salmonis reservoir or natural sources are unknown and transmission mode is still in discussion, but horizontal transmission appears to be the key transmission mode (see Rozas and Enriquez, 2014). Hence, disinfection arise as an important measure to control $P$. salmonis transmission and presence in salmon farms considering its transmission and survival in seawater.

Biosecurity refers to all hygienic practices designed to prevent occurrences of infectious diseases, including preventing introduction of

\footnotetext{
* Corresponding author.

E-mail address: fernando.mardones@unab.cl (F.O. Mardones).
} 
infectious agents, controlling their spread within populations or facilities, and containment or disinfection of infectious materials (Morley, 2002). Prevention and reduction of animal pathogen spread are largely dependent on the principles of good biosecurity, decontamination, disinfection, and sanitation (Ford, 1995). When compared to measures applied to terrestrial animals, biosecurity in aquaculture is still considered a fairly new concept (Subasinghe, 2005). Such lag is largely because of differences in the nature of contacts in the aquatic and terrestrial environments and because intensive aquaculture is a modern concept so disinfection follows that it is also a modern concept. Nowadays, disinfection is commonly used as a disease management tool in aquaculture (Noble and Summerfelt, 1996; Lahnsteiner and Weismann, 2007). Disinfection may be used as a routine practice in biosecurity programs designed to (1) mitigate the risk for incursion of specific diseases (prevention), (2) reduce within-farm disease incidence (control), or (3) to eliminate disease from the population (eradication). The general principles pertaining to the use of disinfection in aquaculture farms involve the application of chemical treatments in sufficient concentrations, and for sufficient periods of time, to neutralize pathogens that would otherwise gain access to surrounding water systems and susceptible populations.

Experimental studies have shown that antibiotics and disinfectants commonly used in aquaculture are effective against Piscirickettsia spp. (Fryer et al., 1990; Fryer et al., 1992). However, such effectiveness, measured under experimental conditions, may be affected in field conditions. Consequently, there is a need for measuring the effectiveness of sanitizers against $P$. salmonis at the farm level in preventing or mitigating pathogen spread. Fish on farms are believed to become infected when they come into contact with water contaminated with $P$. salmonis. Prior to 2007, fish farms in Chile were not regularly fallowed, and fish and equipment were transferred between salt water sites. Therefore, it was likely that $P$. salmonis persisted on farms between year classes and was transferred between farms with fish and equipment movements. However, since 2009 the salmon industry in Chile has adopted several industry wide biosecurity measures, including mandatory fallowing at the farm and neighborhood levels, as well as prohibiting the movement of fish between farms and mandatory disinfection of equipment, which have reduced the likelihood of pathogen transfer between farms and year classes of fish within farms. Despite these efforts, SRS continues to occur in the industry. This raises the concerns of whether this pathogen is endemic in the fish farming area, and whether it is spread through water over such long distances that even neighborhood area fallowing is not sufficient to remove the pathogen. Here, we evaluated differences between and among alternative commercial disinfectants types, doses of application, and time of action in the reduction of $P$. salmonis in vitro assays. Results were used to provide a ranking of products based on their effectiveness that will help to implement protocols to increase biosecurity levels in Chile, ultimately helping to the control of one of the most devastating diseases for the salmon industry of the country.

\section{Materials and products}

\subsection{Commercial disinfectants}

Disinfectants $(n=36)$ were obtained from different commercial sources and were grouped according to the active compound into seven categories including active chlorine dioxides $(n=4)$, inactive chlorine dioxide $(n=4)$, glutaraldehydes $(n=7)$, hypochlorites $(n=8)$, peracetic acids $(n=8)$, peroxides $(n=2)$, and miscellaneous methods (based on quaternary ammonia and orthophthaldehyde) $(n=3)$. Each product was tested in 3 replicates and retested after 1, 5 and $30 \mathrm{~min}$ at low, medium and high disinfection doses as described in Table 1. Median values of the bacterial counts were used as a proxy for testing effectiveness, when compared to results in control samples in which no disinfection procedure was applied.
Table 1

List of disinfectant compounds tested at low, medium and high doses.

\begin{tabular}{ll}
\hline Compounds & Doses (low, medium and high) \\
\hline Active chlorine dioxide & 10,100 and $1000(\mathrm{ppm})$ \\
Inactive chlorine dioxide & 10,100 and $1000(\mathrm{ppm})$ \\
Glutaraldehyde & $0.05,0.5$ and $2(\%)$ \\
Hypochlorite disinfectants & 10,100 and $1000(\mathrm{ppm})$ \\
Hypochlorite detergents & $0.1,1$, and $10(\%)$ \\
Others (quaternary ammonia) & $0.1,1$, and $10(\%)$ \\
Others (orthophaldehyde) & $0.5,5$, and $20(\%)$ \\
Peracetic acid & 10,500 , and $3000(\mathrm{ppm})$ \\
Peroxides & $0.1,1$, and $10(\%)$ \\
\hline
\end{tabular}

\subsection{Propagation and bacterial suspensions}

The $P$. salmonis LF-89 type strain ATCC VR-1361 was acquired from the American Type Culture Collection (ATCC) and stored at $-80^{\circ} \mathrm{C}$ in our cell store collection. $P$. salmonis LF-89 was grown on Cysteine Heart Agar supplemented with $5 \%$ ovine blood (CHAB) (Mikalsen et al., 2008) at $18{ }^{\circ} \mathrm{C}$ for 10 days. Bacterial suspension was prepared using a saline solution $(\mathrm{NaCl} 0,9 \%)$ and adjusting the bacterial concentration to $\sim 0,5$ McFarland.

\subsection{Test conditions and procedures for evaluating bactericidal activity}

For evaluation of bactericidal activity on each product, recommendations to evaluate effectiveness against bacterial diseases of aquaculture relevance provided by the British Standards (BS) European Norm (EN) 1656:2009 were followed. Specifically, temperature was set at $10 \pm 1{ }^{\circ} \mathrm{C}$ and the contact time set as $30 \mathrm{~min} \pm 10 \mathrm{~s}$; interfering substance as organic matter were used throughout the experiments; and all products were tested in hard water, according to standard instructions $\left(1.248 \mathrm{mM} \quad \mathrm{MgCl}_{2}, 3.328 \mathrm{nM} \quad \mathrm{CaCl}_{2}, 2.496 \mathrm{NaHCO}_{3} ; \mathrm{pH}\right.$ $7.0 \pm 0.2$ ). Different concentrations of each product were prepared in hard water at $1.25 \mathrm{x}$ required test concentration.

Each test procedure involved adding $1.0 \mathrm{ml}$ of interfering substance to $1.0 \mathrm{ml}$ of a bacterial test suspension in a sterile glass container, after $8.0 \mathrm{ml}$ of the product (at desired concentration) was added and the mixture was briefly vortexed. The mixture was incubated at $10 \pm 1{ }^{\circ} \mathrm{C}$ for $30 \mathrm{~min}$, following bacterial counts measured in agar plate. Colony forming units $(\mathrm{CFU} / \mathrm{ml})$ were converted into $\log 10 \mathrm{CFU}$. Control tests were processed following a similar protocol, and excluding the use of the disinfectant product.

\subsection{Statistical analyses}

Surviving populations of $P$. salmonis were reported as the median $\mathrm{CFU} / \mathrm{ml}$ from 3 replicate samples, resulting in 972 observations (36 disinfectants, 3 replicates per disinfectant, 3 times, and 3 doses). For statistical analyses, $\mathrm{CFU} / \mathrm{ml}$ values were $\log$ transformed to perform Tukey's Honestly Significant Difference (HSD) tests (Miller, 1981) among different disinfectant types, dose (ppm) and time of exposure (minutes) on the reduction of $P$. salmonis. Confidence intervals on the differences between the $\log \mathrm{CFU} / \mathrm{ml}$ means were based on the range of the sample means rather than the individual differences of the levels of the factors (Yandell, 1997). The intervals returned by this procedure were based on this Studentized range statistics and would only apply exactly to balanced designs where there are the same number of observations made at each level of the compared factors. For all multiple comparisons and statistical tests, a p value of 0.05 was used to determine significance. All analysis were conducted using the statistical software R (R Development Core Team, 2015). 


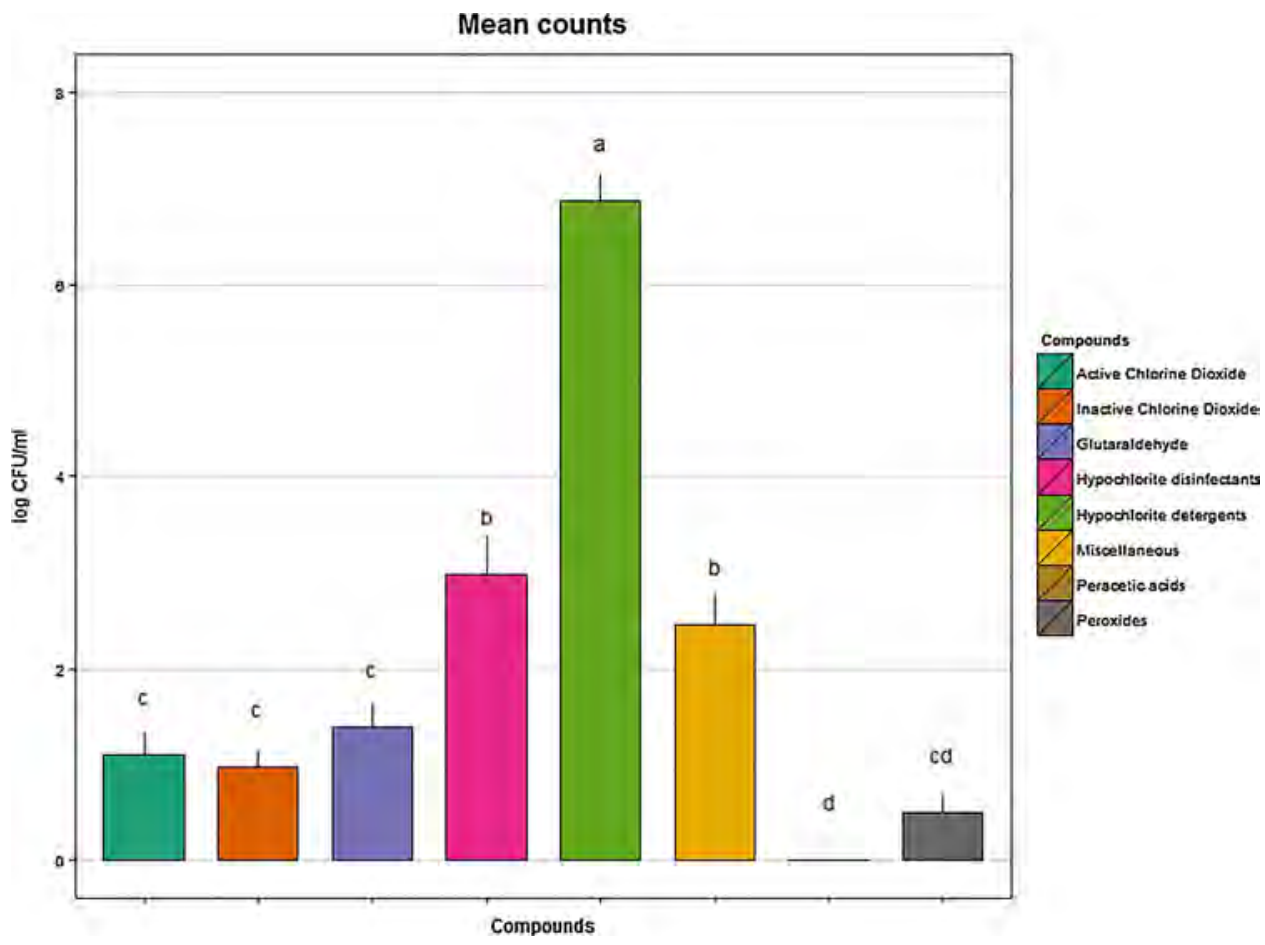

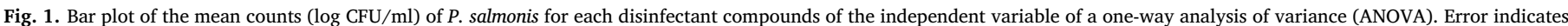
upper standard error of the mean. Bars sharing the same letter are not significantly different according to Tukey's HSD test.

\section{Results}

\subsection{Overall efficacy of sanitizer treatments against $P$. salmonis}

Baseline values for the overall efficacy of disinfectants are provided to define strategies at some targeted efficacy threshold or for comparison with other infectious pathogens in future studies. Log mean counts and total reduction of $P$. salmonis in vitro assays with 7 sanitizers groups are shown in Figs. 1 and 2. Overall mean counts of control samples were approximately $8.6 \log \mathrm{CFU} / \mathrm{ml}$ with a reduction of $6.3 \mathrm{log} \mathrm{CFU} / \mathrm{ml}$ after the challenge (disinfection) with varying times and application doses (Table 2). Disinfection using peracetic acid, peroxides, and both active and inactive chlorine dioxides caused significantly $(\mathrm{P}<0.05)$ higher reduction of $8.56,8.05,7.59,7.45 \log \mathrm{CFU} / \mathrm{ml}$ in samples, respectively,

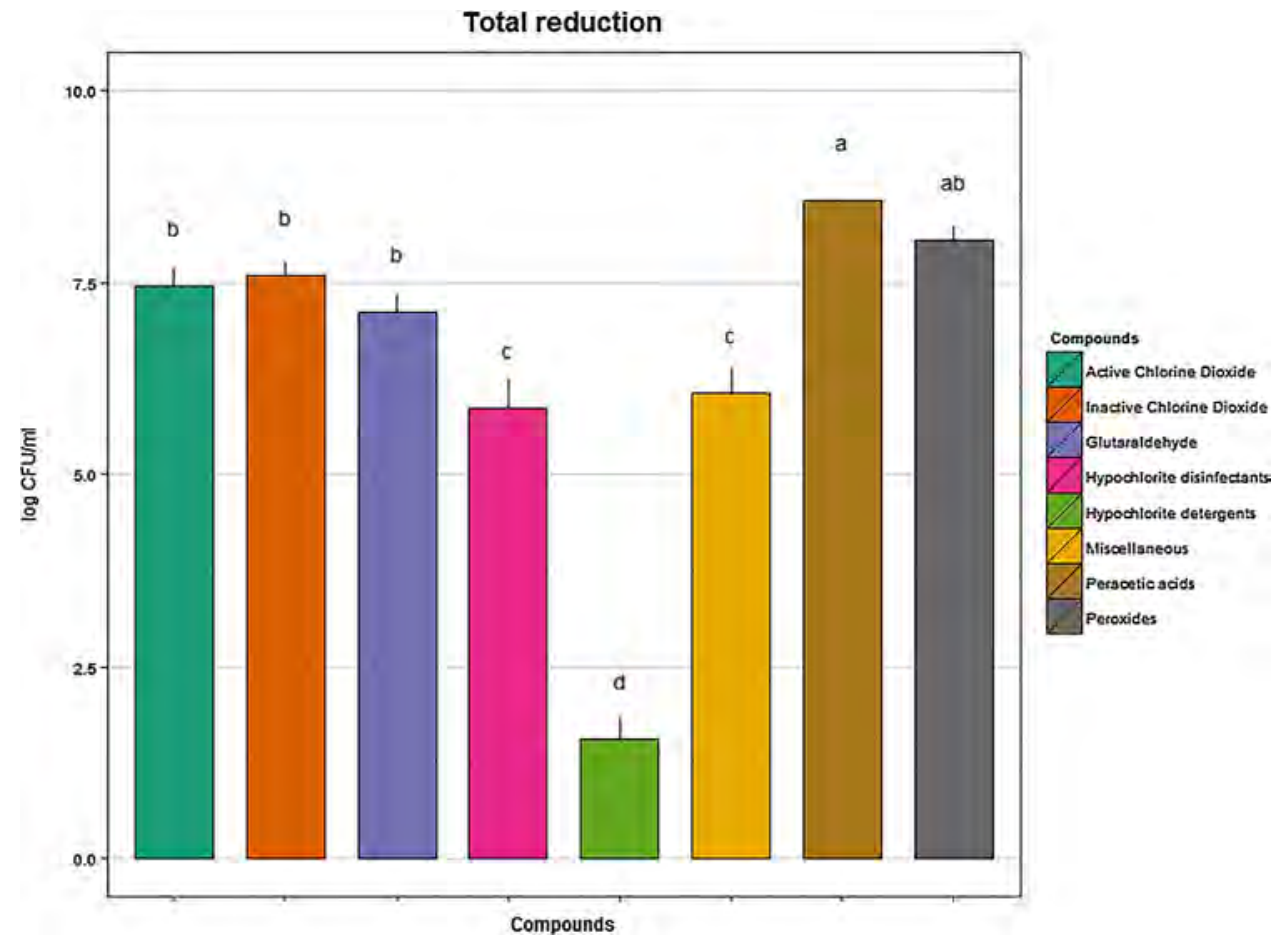

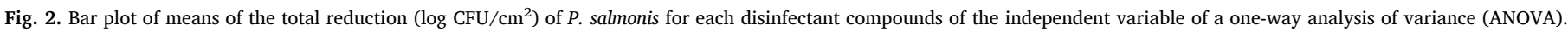
Error indicates upper standard error of the mean. Bars sharing the same letter are not significantly different according to Tukey's HSD test. 
Table 2

Mean counts $(\log \mathrm{CFU} / \mathrm{ml})$ and standard deviation $( \pm)$ of $P$. salmonis for each disinfectant compounds. Bolded letters indicate disinfectant compounds with statistically significant reduction.

\begin{tabular}{lll}
\hline Compounds & \multicolumn{2}{l}{ Disinfection } \\
\cline { 2 - 3 } & Control & Treatment \\
\hline Active chlorine dioxide & $8.56 \pm 0.06$ & $1.11 \pm 2.35$ \\
Inactive chlorine dioxide & $8.44 \pm 0.08$ & $6.88 \pm 2.76$ \\
Glutaraldehyde & $8.56 \pm 0.12$ & $0.97 \pm 2.19$ \\
Hypochlorite disinfectants & $8.51 \pm 0.12$ & $1.39 \pm 2.66$ \\
Hypochlorite detergents & $8.85 \pm 0.09$ & $2.99 \pm 3.52$ \\
Others & $8.51 \pm 0.15$ & $2.45 \pm 2.92$ \\
Peracetic acid & $8.56 \pm 0.10$ & $0.00 \pm 0.00$ \\
Peroxides & $8.54 \pm 0.09$ & $0.49 \pm 1.41$ \\
\hline
\end{tabular}

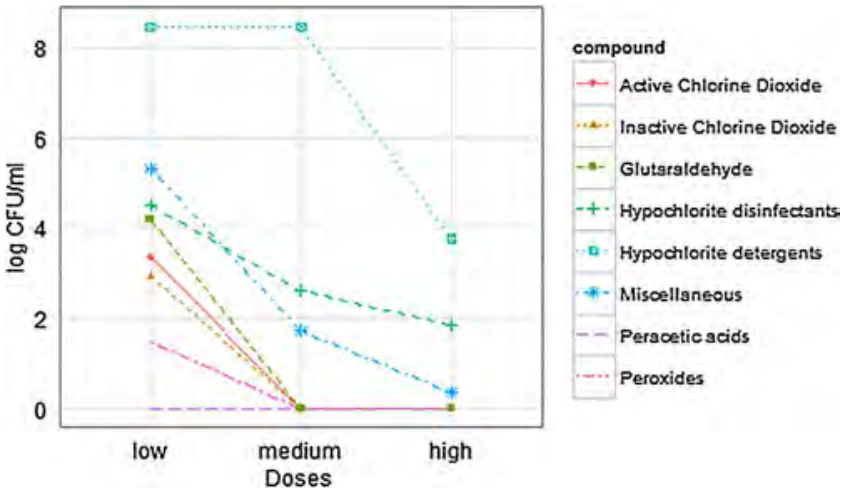

Fig. 3. Effect of doses and the effectiveness for each disinfectant compounds in the mean counts (log $\mathrm{CFU} / \mathrm{ml})$ of $P$. salmonis.

compared to other tested sanitizers. Lowest reduction was obtained after disinfection with hypochlorite detergents (1.56 log CFU/ml).

\subsection{Efficacy of sanitizer treatments varying with doses}

As doses increased, overall counts of $P$. salmonis decreased (Fig. 3). At low doses, only use of peracetic acids resulted in zero counts of CFU/ $\mathrm{ml}$. At medium doses, most disinfectants showed counts of zero with the exception of hypochlorite disinfectants, detergents, and others. Similar results were obtained at highest dose levels.

\subsection{Efficacy of sanitizer treatments varying in time}

As disinfection time increases, overall counts of $P$. salmonis decreased (Fig. 4). Whereas at $1 \mathrm{~min}$, only the peracetic acids showed zero counts of $\mathrm{CFU} / \mathrm{ml}$, increasing time to 5 min resulted in zero counts for both peracetic acids and peroxides. All other disinfectants showed counts for P. salmonis, and after $30 \mathrm{~min}$ of exposure, three sanitizers (others, and hypochlorite disinfectants and detergents) were not able to considerably lower $P$. salmonis counts. Interactions between compounds, doses, and times are shown in Fig. 5.

\section{Discussion}

P. salmonis is, arguably, the most important threat to the sustainability of the Chilean salmon industry and this study greatly contributes to the implementation of effective biosecurity strategies through the use of disinfectants that inactivate the bacterium. Most disinfectants compounds were effective in reducing the number of bacteria; however, peracetic acid and peroxides demonstrated significantly higher reduction compared to other sanitizers, considering doses and disinfection times. On the other hand, both hypochlorides (detergents and disinfectants) showed poor performances in general. The study suggests that

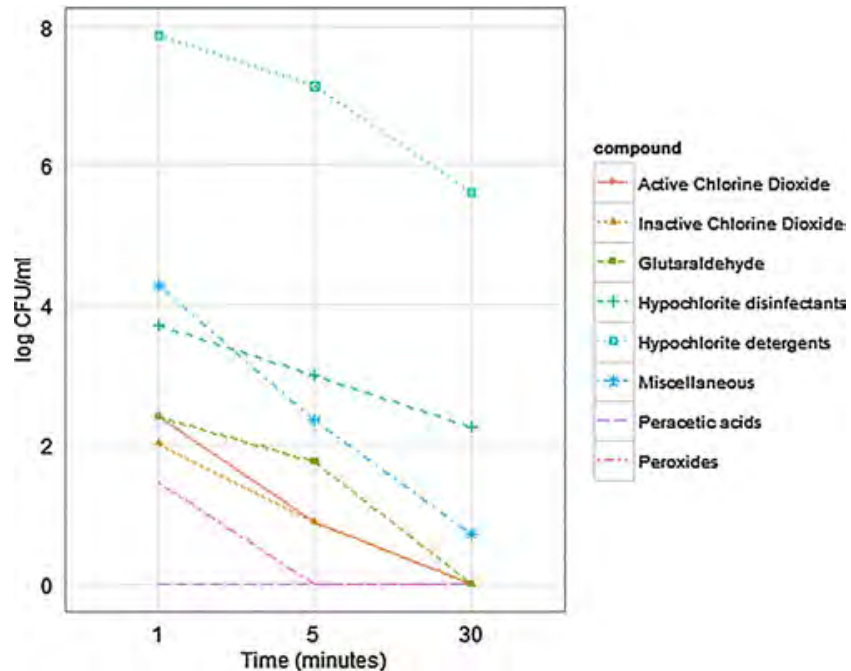

Fig. 4. Effect of time and the effectiveness for each disinfectant compounds in the mean counts (log $\mathrm{CFU} / \mathrm{ml})$ of $P$. salmonis.

the use of peracetic acid for $1 \mathrm{~min}$ at $10 \mathrm{ppm}$ would be the best choice for any biosecurity measures that require the use of disinfectants to prevent and minimize the spread of $P$. salmonis. Alternatively, a range of disinfectants including active and inactive chlorine dioxides, glutaraldehyde, peracetic acids, and peroxides at medium doses would result in elimination of the bacteria within $5 \mathrm{~min}$.

Peracetic acid was found to be the most effective disinfectant compound followed by the peroxides. The peracetic acid contains hydrogen peroxide in a mixture with acetic acid in an aqueous solution, explaining, at least in part, why peroxides alone are less effective than peracetic acid (Kitis, 2004). The peracetic acid is characterized by rapid action against all microorganisms, maintaining its efficacy in the presence of organic soil that has been applied for bacteria and fungi removal from fruits and vegetables since the early 1950's (Block, 2001; Kitis, 2004). Although little is known about its mechanism of action, it is believed to function similarly to other oxidizing agents, i.e., it denatures proteins, disrupts the cell wall permeability, and oxidizes sulfhydryl and sulfur bonds in proteins, enzymes, and other metabolites (Block, 2001). Special advantages of peracetic acid are that it does not result in harmful decomposition products (i.e., acetic acid, water, oxygen, hydrogen peroxide), enhances removal of organic material, and leaves no residue. Peracetic acid has been widely used to treat municipal waste water due to its strong antimicrobial activity (Kitis, 2004; Koivunen and Heinonen-Tanski, 2005; Falsanisi et al., 2006; Rossi et al., 2007). It has also been tested as a disinfectant to be used in fish aquaculture (Lahnsteiner and Weismann, 2007) and it has shown potential as a treatment chemical against fish pathogens (RintamakiKinnunen et al., 2005a,b; Meineilt et al., 2007; Meinelt et al., 2007). Furthermore, its degradation time and kinetics would be suitable for aquaculture (Pedersen et al., 2009).

Hydrogen peroxide was discovered in 1818 and its use as a disinfectant was first proposed in 1891(Linley et al., 2012) showing an important activity against a wide range of microorganisms, including bacteria, yeasts, fungi, viruses, and spores (Sattar et al., 1998). Hydrogen peroxide works by producing destructive hydroxyl free radicals that can attack membrane lipids, DNA, and other essential cell components (Linley et al., 2012). Catalase, produced by aerobic organisms and facultative anaerobes that possess cytochrome systems, may protect cells by degrading hydrogen peroxide to water and oxygen (Block, 2001), however, this mechanism of defense is overwhelmed by the concentrations used for disinfection as has shown here.

Both products are able to mitigate diseases without harming the fish and leaving any dangerous residues in the environment (Meinelt et al., 2015). This feature is important because environmental cleanliness and 


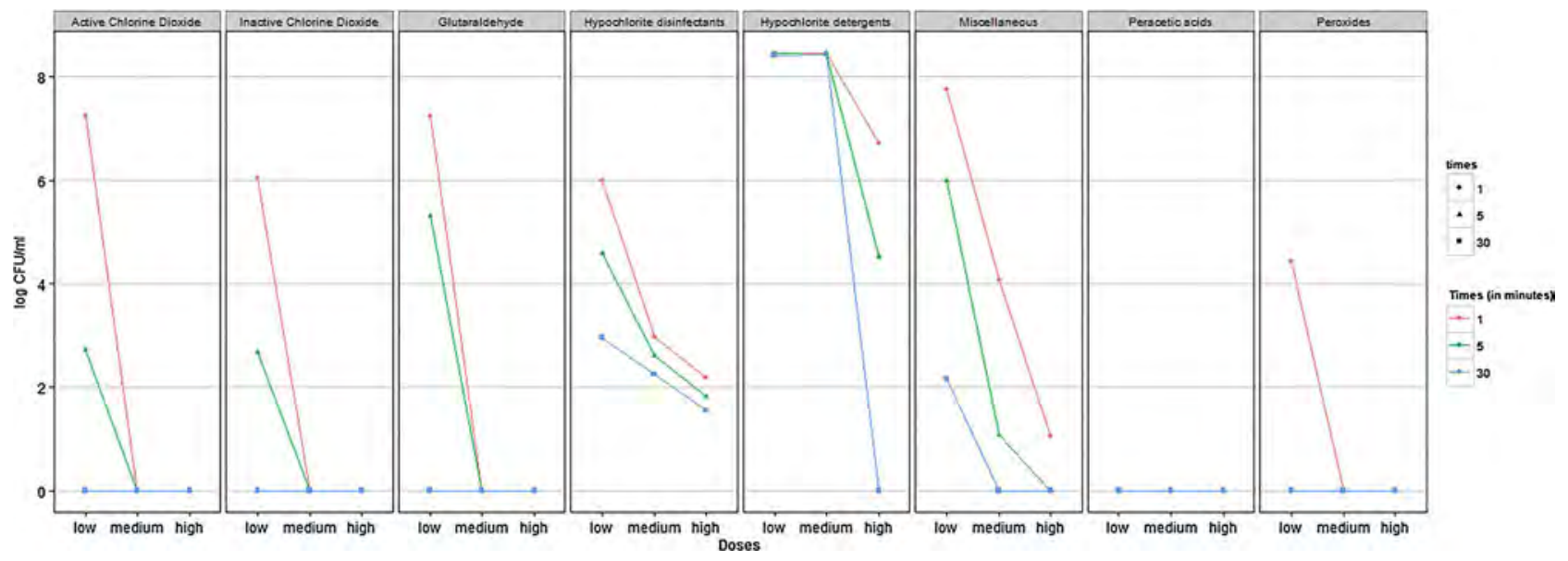

Fig. 5. Effect of doses and times for the effectiveness for each disinfectant compounds in the mean counts (log CFU/ml) of P. salmonis.

waste disposal are crucial for biosecurity plans that should be reinforced in the routine practices. Peracetic acid and peroxides appear to provide an optimal combination of disinfection success while avoiding the more environmentally harmful consequences common to chemical use.

Cleaning and disinfection procedures for the infrastructure and portable fomites are an integral part of the Chilean salmon production as described elsewhere (Soon et al., 2015). Biosecurity in Chilean salmon industry is a shared effort among broodstock; hatchery; fry, fingerling, and smolt units; and the grow-out production (Soon et al., 2015). However, because SRS is a disease that affects primarily farmed salmon during the grow out stage (or fattening), biosecurity practices among salmon farms should be stricter in this phase. Disinfection procedures are implemented in live organisms such as eggs before incubation, in inert materials including materials used for mortality removal, boats, well-boats and in the disinfection of water sources. Clothing, equipment, and vehicles may easily become contaminated with infectious agents, and veterinarians might become vectors for disease transmission unwittingly as they move among animal populations. Staff's hygiene and sanitization include disinfection of rubber boots and hands and the use of footbaths in boats, at the farm site, and at the sea cages site. All personnel that contact fish or subproducts are required to wear clean, appropriate attire at all times. The study here contributes to the identification of effective disinfectants and treatments towards a standardized approach for meeting national and international aquaculture biosecurity requirements for preventing and controlling P. salmonis (Palic et al., 2015). Effective biosecurity measures, together with other practical management applications in animal production, ultimately contribute to the decrease of mortality-associated expenses and to boost food production (Ford, 1995).

\section{Conclusions}

This study provides the first quantification of the effectiveness of several disinfectants that are used in the Chilean salmon industry. These products are used in key aspects of biosecurity programs established throughout the salmon production stages, such as sanitization of contact surfaces, treatment of wastewater discharges, and implementation of hygiene procedures (hand wash, foot baths). Selection of an adequate disinfection protocol, including type, doses and time of exposure, will be key for the success of biosecurity programs aimed to minimize $P$. salmonis transmission. Ultimately, prevention and control of, arguably, one of the most economically important diseases affecting Chilean salmon aquaculture requires evidence-based disinfectant selection as part of larger biosecurity measures.

\section{Acknowledgments}

This research was funded by CORFO-INNOVA project No 12BPC213531 and projects funded by the Chilean Fund for Scientific and Technological Development (FONDECYT) Project 3140235 and the Minnesota's Discovery, Research and InnoVation Economy (MNDRIVE). We thank industry representatives that were willing to participate in this project. The Ministerio de Educación of Spain is acknowledged by the FPU/MEC doctorate fellowship for Ana Muniesa.

\section{References}

Block, S.S., 2001. Disinfection, Sterilization, and Preservation. Lippincott Williams \& Wilkins, Philadelphia, PA.

Bravo, S., Campos, M., 1989. Coho Salmon Syndrome in Chile. Fish Health Section Newsletter. American Fisheries Society, pp. 3.

Cusack, R.R., Groman, D.B., Jones, S.R.M., 2002. Rickettsial infection in farmed Atlantic salmon in eastern Canada. Can. Vet. J. 43, 435-440.

Falsanisi, D., Gehr, R., Santoro, D., Dell'Erba, A., Notarnicola, M., Liberti, L., 2006. Kinetics of PAA demand and its implications on disinfection of wastewaters. Water Qual. Res. J. Can. 41, 398-409.

Ford, W.B., 1995. Disinfection procedures for personnel and vehicles entering and leaving contaminated premises. Rev. Sci. Tech. OIE 14, 393-401.

Fryer, J.L., Lannan, C.N., Garces, L.H., Larenas, J.J., Smith, P.A., 1990. Isolation of a rickettsiales-like organism from diseased coho salmon (Oncorhynchus-Kisutch) in Chile. Fish Pathol. 25, 107-114.

Fryer, J.L., Lannan, C.N., Giovannoni, S.J., Wood, N.D., 1992. Piscirickettsia salmonis gen. nov. sp. nov., the causative agent of an epizootic disease in salmonid fishes. Int. J. Syst. Bacteriol. 42, 120-126.

Kitis, M., 2004. Disinfection of wastewater with peracetic acid: a review. Environ. Int. 30, 47-55.

Koivunen, J., Heinonen-Tanski, H., 2005. Inactivation of enteric microorganisms with chemical disinfectants, UV irradiation and combined chemical/UV treatments. Water Res. 39, 1519-1526.

Lahnsteiner, F., Weismann, T., 2007. Treatment of ichthyophthiriasis in rainbow trout and common carp with common and alternative therapeutics. J. Aquat. Anim. Health 19, 186-194.

Lannan, C.N., Fryer, J.L., 1994. Extracellular survival of Piscirickettsia-Salmonis. J. Fish Dis. $17,545-548$.

Leal, J., Woywood, D., 2007. Piscirickettsiosis en Chile: avances y perspectivas para su control. Salmociencia 2, 34-42.

Linley, E., Denyer, S.P., McDonnell, G., Simons, C., Maillard, J.Y., 2012. Use of hydrogen peroxide as a biocide: new consideration of its mechanisms of biocidal action. J. Antimicrob. Chemother. 67, 1589-1596.

Marshall, S.H., Conejeros, P., Zahr, M., Olivares, J., Gomez, F., Cataldo, P., Henriquez, V., 2007. Immunological characterization of a bacterial protein isolated from salmonid fish naturally infected with Piscirickettsia salmonis. Vaccine 25, 2095-2102.

Meineilt, T., Richert, I., Stuber, A., Braunig, I., 2007. Application of peracetic acid to the parasite Ichthyophthirius multifilis in Sander (Sander lucioperca) breeding. Dtsch. Tierarztl. Wochenschr. 114, 244-251.

Meinelt, T., Staaks, J., Staaks, G., Stueber, A., Braunig, I., 2007. Anti-parasitic effects of peracetic acid (PAA) to free infective stages (Theronts) of the white spot disease, Ichthyophthirius multifiliis in vitro. Dtsch. Tierarztl. Wochenschr. 114, 384-387.

Meinelt, T., Phan, T.M., Behrens, S., Wienke, A., Pedersen, L.F., Liu, D.B., Straus, D.L. 2015. Growth inhibition of Aeromonas salmonicida and Yersinia ruckeri by disinfectants containing peracetic acid. Dis. Aquat. Organ. 113, 207-213.

Mikalsen, J., Skjaervik, O., Wiik-Nielsen, J., Wasmuth, M.A., Colquhoun, D.J., 2008. Agar 
culture of Piscirickettsia salmonis, a serious pathogen of farmed salmonid and marine fish. FEMS Microbiol. Lett. 278, 43-47.

Miller, P.G., 1981. Simultaneous Statistical Inference. Springer-Verlag, New York, NY. Morley, P.S., 2002. Biosecurity of veterinary practices. Vet. Clin. N. Am. Food Anim. Pract. 18, 133-.

Noble, A.C., Summerfelt, S.T., 1996. Diseases encountered in rainbow trout cultured in recirculating systems. Annu. Rev. Fish Dis. 6, 65-92.

Olsen, A.B., Melby, H.P., Speilberg, L., Evensen, O., Hastein, T., 1997. Piscirickettsia salmonis infection in Atlantic salmon Salmo salar in Norway-epidemiological, pathological and microbiological findings. Dis. Aquat. Organ. 31, 35-48.

Palic, D., Scarfe, D.A., Walster, C.I., 2015. A standardized approach for meeting national and international aquaculture biosecurity requirements for preventing, controlling, and eradicating infectious diseases. J. Appl. Aquacult. 27, 185-219.

Pedersen, L.F., Pedersen, P.B., Nielsen, J.L., Nielsen, P.H., 2009. Peracetic acid degradation and effects on nitrification in recirculating aquaculture systems. Aquaculture 296, 246-254.

R Development Core Team, 2015. R: A Language and Environment for Statistical Computing. R Foundation for Statistical Computing, Vienna, Austria.

Rintamaki-Kinnunen, P., Rahkonen, M., Mannermaa-Keranen, A.L., Suomalainen, L.R., Mykra, H., Valtonen, E.T., 2005a. Treatment of ichthyophthiriasis after malachite green. I. Concrete tanks at salmonid farms. Dis. Aquat. Organ. 64, 69-76.

Rintamaki-Kinnunen, P., Rahkonen, M., Mykra, H., Valtonen, E.T., 2005b. Treatment of ichthyophthiriasis after malachite green. II. Earth ponds at salmonid farms. Dis. Aquat. Organ. 66, 15-20.

Rossi, S., Antonelli, M., Mezzanotte, V., Nurizzo, C., 2007. Peracetic acid disinfection: a feasible alternative to wastewater chlorination. Water Environ. Res. 79, 341-350.

Rozas, M., Enriquez, R., 2014. Piscirickettsiosis and Piscirickettsia salmonis in fish: a review. J. Fish Dis. 37, 163-188.

Sattar, S.A., Springthorpe, V.S., Rochon, M., 1998. A product based on accelerated and stabilized hydrogen peroxide: evidence for broad-spectrum germicidal activity. Can. J. Infect Control 123-130.

Soon, J.M., Pavez, B., Baines, R.N., 2015. Have you disinfected your boots? A case study of food safety and biosecurity practices of a salmon farm in Chile. J. Appl. Aquacult. $27,228-248$

Subasinghe, R.R., 2005. Epidemiological approach to aquatic animal health management: opportunities and challenges for developing countries to increase aquatic production through aquaculture. Prev. Vet. Med. 67, 117-124.

Yandell, B.S., 1997. Practical Data Analysis for Designed Experiments. Chapman \& Hall, London, UK. 